\title{
Learning science through argumentative synthesis writing and deliberative dialogues: a comprehensive and effective methodology in secondary education
}

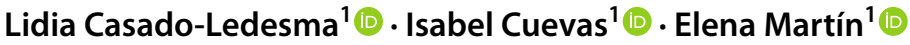

Accepted: 10 July 2021 / Published online: 14 August 2021

(c) The Author(s) 2021, corrected publication 2021

\begin{abstract}
Scientific literacy can be promoted through oral and written argumentative practice. Collaborative discourse has proven effective in fostering conceptual understanding, especially when discussions are developed under deliberative goals. Likewise, writing tasks as argumentative syntheses stand out for its epistemic value and its contribution to constructive learning processes. However, there are no known educational interventions that have combined these two didactic activities to teach science. The objective of this research was to compare the impact of four intervention programs, based on deliberative dialogues and argumentative synthesis writing activities, on the learning of socio-scientific content. The four programs resulted from the combination of two instructional components (Explicit Instruction; Guide), while deliberative dialogues and argumentative syntheses were constant elements. We conducted a pre-post quasi-experimental study in which participated 151 Spanish third grade secondary school students. Socio-scientific learning was evaluated through a content test made up of open questions. The results showed all students progressed in their socio-scientific knowledge. Instructional practices did not have a direct effect on content learning. However, we observed an indirect effect of explicit instruction on learning socio-scientific content, through learning of argumentative synthesis writing. Besides, we found a positive relation between progression in synthesis writing and knowledge acquisition.
\end{abstract}

Keywords Secondary education - Learning science - Deliberative discussions · Written synthesis

Lidia Casado-Ledesma

casadoledesma.lidia@gmail.com

Extended author information available on the last page of the article 


\section{Introduction}

Science in school contexts is frequently treated from a positivist approach (Holbrook \& Rannikmae, 2007). According to this epistemological perspective, a right answer exists, truth claims are based on observation and data lead unequivocally to conclusions (Cawthron \& Rowell, 1978). Nevertheless, assessing alternatives, weighing evidence, juxtaposing competing claims, and evaluating the potential validity of scientific claims are all essential to construct scientific arguments. The practices of experts in this field show that science is a social process of knowledge construction in which the conjecture, rhetoric and argument are closely related (Schwarz, 2009).

Science education has to consider the social and dialogic nature of knowledge. Students can no longer be passive recipients of theories "discovered" by expert scientists and "transmitted" by teachers. Science curriculum should be focused on what students need to do to learn science instead of transmitting mere contents. Kuhn (2005) establishes the goal of science education as promoting a way of thinking in which inquiry and argument are two central skills, and, as Duschl (2008) argues, it is necessary to embody the dialogic building processes that are at the core of this field of knowledge. Moreover, argumentation activities are necessary to develop students' reasoning, metacognitive, communication, and thinking skills, thus increasing their scientific literacy (Lazarou et al., 2017). The use of scientific argument activity in scholar settings contributes to the students' critical thinking development (Lazarou et al., 2017; Rayner \& Papakonstantinou, 2018), which is an indispensable objective in school curriculum (OECD, 2018). Hence, methodologies based on active participation must be promoted in order to involve students on debates about relevant scientific topics (Driver et al., 2000; Sadler \& Zeidler, 2004a).

Debates about scientific issues may entail ethical implications. Consequently, one of the main goals of science education is to show the dependency relationships between science and society. The concept of socio-scientific issues arises as a way of describing social dilemmas linked to scientific fields (Gayford, 2002; Sadler et al., 2004; Zeidler et al., 2002). Socio-scientific issues are controversial topics with social implications in economic, political, and ethical terms. Energy resources, birth control or genetically modified foods are just some of the socioscientific dilemmas that society faces nowadays. Several positions can be identified when these topics are debated. In this sense, reaching a conclusion about a socio-scientific issue could be seen as a poorly structured, open-ended problem with no definitive, correct answers (Kuhn, 1991). The type of thinking that emerges when socio-scientific issues are considered is the informal reasoning (Means \& Voss, 1996), in which argumentation skills play an important role (Sadler \& Zeidler, 2004b). Individuals need to weigh up arguments related to the risks and benefits of the different sides, as well as to assess the data critically, before making informed and balanced decisions about socio-scientific problems. These are demanding processes for students, due to the confirmation bias phenomenon, which is a widely studied reasoning bias, defined as the tendency to 
choose and interpret evidence according to previous beliefs (Nickerson, 1998). However, there is evidence that argumentative dialogue may mitigate confirmation bias effects when discourse goals promote deliberation versus persuasion (Villarroel et al., 2016). Therefore, discussions about socio-scientific issues are suitable activities to elicit argumentation processes and to develop scientific literacy (Dawson \& Venville, 2009). Furthermore, they can foster students' reasoning abilities as two-sided reasoning (Nussbaum, 2008a), especially when these dialogues aim at reaching an integrative solution.

In addition to deliberative discussions, writing tasks can be effective to bring about a deep understanding of contents (Yore et al., 2003). However, according to Patterson (2001), the use of writing as a teaching method to develop students' scientific understanding is uncommon. Traditional writing tasks in science have been focused on keeping accurate records, completing laboratory reports, and demonstrating an understanding of concepts for assessment purposes (Syh-Jong, 2007), which are activities that lead to transmission of knowledge instead of its transformation (Bereiter \& Scardamalia, 1987). Unlike these writing tasks, argumentative synthesis writing from sources with conflicting information is a modality of writing that stands out for its epistemic potential (Mateos et al., 2018). It requires identifying, contrasting, an integrating arguments and counterarguments that support the different perspectives about a controversial issue. These strategies facilitate the resolution of the cognitive conflict generated within the activity, promoting a greater understanding of the sources and the connections between them (Barzilai et al., 2018). Several interventions haven been developed to teach students how to write argumentative synthesis texts (Casado-Ledesma et al., 2021; González-Lamas et al., 2016; Granado-Peinado et al., 2019; Mateos et al., 2018), showing that instructional practices are required to help students to overcome their tendency to argue in favor of a single position.

Individuals need to use oral and written language to do science, to construct new understandings of scientific ideas, and to inform other people about science (Yore et al., 2003). Research has demonstrated that discussions in combination with writing activities are effective methodologies to facilitate the learning of scientific content (Mason, 2001; Rivard \& Straw, 2000; Syh-Jong, 2007). This article presents a didactic proposal to further the learning of scientific contents in secondary school students. We aimed to promote scientific literacy through the following learning activities with demonstrated epistemic value: (1) dialogic activities about socioscientific problems with a deliberative goal, and (2) argumentative synthesis writing from sources with conflicting information related to socio-scientific issues. We designed four intervention modalities in which written and dialogic practice were combined with different instructional methods, in order to compare their impact in the learning of socio-scientific content.

\section{Learning science by arguing: the value of deliberative dialogues}

Argumentation is central to scientific thinking (Driver et al., 2000; Duschl \& Osborne, 2002; Kuhn, 1993). The construction of scientific knowledge consists in 
making propositions supported by evidence, which are debated, reviewed and criticised within expert communities (Dawson \& Venville, 2009). Argumentation is, therefore, the discourse of those who practice science.

Discursive practices are not only essential to articulate scientific arguments, but also to enhance science learning (Erduran et al., 2004; Garcia-Mila \& Andersen, 2007). There is a broad consensus about the contribution of argumentation and collaborative discourse to conceptual understanding (Nussbaum, 2008b). Practices in which students are involved in oral discussions where they have to evaluate arguments and counterarguments are effective to promote deeper learning of content. In addition, engagement in critical, elaborative discourse can help maintain learning gains over time (Asterhan \& Schwarz, 2007). There are several studies that support the connection between argumentation and learning of scientific contents. Findings from von Aufschnaiter et al.'s (2008) research indicated that small group and classroom argumentative discussions allowed high school students to consolidate a wide range of scientific concepts. Jiménez-Aleixandre (2002) found similar results, showing that when adolescents are engaged in argumentation and decision making about environmental management, they are able to apply ecological concepts to practical contexts, integrating conceptual knowledge with values. Zohar and Nemet (2002) conducted a study in which students who have previously received explicit instruction on the qualities of good arguments, scored higher on a human genetics test. The authors suggest collaborative discussions allowed these students to better integrate new knowledge with prior knowledge. Larraín et al. (2019) developed an intervention in which they compared the learning results from two instructional modalities, implemented during the same didactic unit in the science subject: a methodology based on dialogic and argumentative classroom talk, and a traditional methodology. Students were assessed individually using both immediate and delayed post-test measures of science content knowledge. The results showed no differences in pre to post immediate content knowledge between conditions. However, students who were taught through dialogic activities increased their scientific content knowledge significantly more than the other group between post-immediate and post-delayed tests.

Studies such as the above-mentioned suggest argumentation drives conceptual change by making students' beliefs explicit and open to evaluation (Kuhn, 1991). Discussion activities provide the opportunities to examine different perspectives and to process the statements more deeply. When students argue in knowledge-construction activities, they are developing a deep understanding of the matter under discussion (Leitão, 2000; Schwarz, 2009), but also argumentative skills manifested in the dialogue with others and with themselves through inner argumentative language (Larraín, 2017). Therefore, peer discussions contribute to revise one's thinking, evaluating the ideas under scrutiny and using semiotic resources of argumentation to unfold metacognitive activity (Larraín et al., 2019). However, although argumentative dialogue can improve content learning and argument quality, the benefits are mediated by individuals' task goals while arguing. Felton et al. (2009) conducted a study in which they compared the learning gains regarding the aim of the discussions: a persuasive dialogue (argue to convince the partner) versus a deliberative one (argue to reach a consensus). The authors found that students who participated in deliberative dialogues achieved better results on content learning 
compared to the participants in persuasion-dialogue group. This evidence suggests that when students are involved in consensus building to reach an integrative position, instead of defending a single opinion, they are more likely to understand and recall information.

Deliberative dialogue is a type of dialogue characterized by exploring different perspectives on a controversial topic, in order to reconcile the positions and to reach a collaborative, reasoned and well-founded conclusion (Walton, 2010). This approach to the discussion is especially meaningful when students engage in decision-making tasks (Rapanta \& Christodoulou, 2019). Socio-scientific problems do not have evident solutions and they require weighing different alternatives before reaching a conclusion about them. In this sense, deliberative dialogue may be an appropriate approach to make decision about socio-scientific issues. Furthermore, deliberative dialogues mitigate the effects of confirmation-bias (Nickerson, 1998), contributing to the integration of arguments and counterarguments from different perspectives (Villarroel et al., 2016). Consequently, discussions with a deliberative goal, instead of a persuasive one, engage students in a dialectical process, which enhance their argumentation skills and their scientific understanding.

\section{Learning science by writing argumentative texts: the value of argumentative synthesis writing}

Argumentative writing is an infrequent task in science subjects (Patterson, 2001; Syh-Jong, 2007). Several studies reveal science teachers underestimate its relevance, as well as the need of instruction to improve argumentative skills (Fulwiler, 2008; Kiuhara et al., 2009). Nevertheless, the exercise of writing an argumentative text may help students to develop a better understanding of core ideas of science. The processes involved in argumentative writing (e.g. reflection, elaboration, interpretation, synthesis, and justification) requires the writer to think deeply about the content and its validity, which contributes in turn to knowledge acquisition (Sampson et al., 2013). A good example of writing task that stands out for its epistemic value and its contribution to knowledge building processes is argumentative synthesis writing from sources with conflicting information.

According to Mateos et al. (2018), argumentative synthesis writing from sources with conflicting information is a modality of writing essay in which the objective is to reconcile alternative perspectives about a controversy. To achieve this purpose, it is necessary to identify the arguments and counterarguments related to the different sides of the problem, compare them and finally, create a new and original text with an integrative conclusion. Nussbaum and Schraw (2007) propose three strategies to integrate arguments and counterarguments: refutation, which consists in arguing against the contrary position looking for revealing its weakness; weighing, when the writers analyse advantages and disadvantages of both sides, and conclude that the evidence supporting a position is stronger than the opposite one; and, lastly, synthesising, when the conclusion includes an integrative solution that combines the benefits of both perspectives. Weighing and synthesising strategies are related to two-sided reasoning 
(Nussbaum, 2008a) and, unlike refutation strategy, they involve posture reconciliation. Examining the relationship between arguments and counterarguments is an essential element in argumentative synthesis tasks. Achieving an effective integration of both contributes to the development of critical thinking and to the learning of specific contents with a long-term effect (Nussbaum \& Schraw, 2007; Nussbaum, 2008b). When documentary sources present apparently contradictory information, it is necessary to recognize the conflicts, contrast the different points of view and solve the disagreement, seeking the integration of positions. These processes lead to a better understanding of the sources and the connections between them (Barzilai et al., 2018). This is the reason why argumentative synthesis writing from sources with conflicting information promote constructive learning and reinforce the ability to take perspective (Mateos et al., 2014; Nelson, 2008; Wiley et al., 2014).

Argumentative synthesis writing from multiple sources is a cognitive demanding activity with a great epistemic potential. It requires the mobilization of different strategies related to recursive reading, the selection of information and the integration of different elements to compose a new original text with specific structure and content (Segev-Miller, 2007). It is a hybrid task, since it involves acting as readers and writers in order to reorganise the information from the sources, select the most important ideas and then elaborate a new text that connects them (Spivey, 1997). Research has revealed that students tend to argue in favor of a single point of view, without considering or rebutting an opposing side, when they are asked to write argumentative texts (Nussbaum \& Kardash, 2005; Nussbaum \& Schraw, 2007; Wolfe et al., 2009). Learning to write argumentative synthesis involves overcoming the tendency to build one-sided arguments when presenting conflicting positions about an issue.

In line with the interventions in the field of argumentative writing and in the field of syntheses from multiple sources, we have carried out a set of studies in which instructional programs were designed specifically aimed at teaching argumentative synthesis writing from sources with conflicting information. González-Lamas et al. (2016) conducted a study in which they trained secondary school students in self-regulation strategies, in order to improve their argumentative synthesis writing. They found the instruction based on self-regulation strategies through a video modelling session and the support of a guide allowed students to integrate arguments and counterarguments. Mateos et al. (2018) found university students were able to integrate conflicting information in their argumentative synthesis when they had previously received explicit instruction, combined with the use of a guide and collaborative practice. Besides, Granado-Peinado et al. (2019) designed a program for higher education that included collaborative practice and a written guide, supported by explicit instruction about how to write collaborative argumentative syntheses and how to cooperate with the partner during the writing tasks. This program was compared with three others in which they progressively reduced the aids provided (explicit instruction with video modelling, guide and collaborative practice). Results showed students from intervention programs with the explicit instruction component (about argumentative synthesis writing and collaborative processes) elaborated more integrative synthesis. 
These studies have evidenced the positive effect of different instructional practices on the ability to integrate arguments and counterarguments. However, none of these interventions has explored the contribution of these instructional practices, aimed at teaching argumentative synthesis writing from conflicting sources to the learning of specific contents about the controversial issues.

\section{This study}

Argumentation research has traditionally been framed in two theoretical perspectives. From the "arguing to learn" perspective, the statement is that engaging in dialogical argumentation with peers may promote students' knowledge acquisition (Andriessen \& Baker, 2014; Asterhan \& Schwarz, 2016; Weinberger \& Fischer, 2006). On the contrary, from the "learning to argue" perspective, argumentation is seen as a valuable practice in its own. Therefore, those maintaining this last conception, design interventions aimed to enhance students' skills in both dialogic and individual written or verbal argument (Kuhn et al., 2015; Resnick et al., 2015).

Our research intends to integrate both approaches. Firstly, and in line with previous interventions in the field of argumentative synthesis writing (González-Lamas et al., 2016; Granado-Peinado et al., 2019; Mateos et al., 2018), our study aimed to promote the individual argumentative skills which are involved in this writing modality. We designed four intervention programs, conducted in secondary education, whose efficacy was compared. The four programs resulted from the combination of two instructional components (explicit instruction with video modelling and a written guide), while deliberative dialogues (Walton, 2010) were a constant element. Results, reported in Casado-Ledesma et al. (2021), revealed that explicit instruction, in combination with deliberative dialogues, was the most beneficial instructional practice for learning argumentative synthesis writing. The influence of instructional practices depended on the quality indicator of the synthesis considered (coverage of arguments or integration level), showing different learning paths. In this article we analyse the second objective of the study: to promote scientific literacy related to socio-scientific problems through student participation in these intervention programs.

The general objective of the current study is to evaluate the effects of four intervention programs, based on oral and written argumentation activities, on the learning of scientific content in secondary school students. The intervention programs include deliberative dialogue activities, preceded by different instructional practices, and argumentative synthesis writing tasks.

In particular, the specific objectives are:

1. To assess the effect of different instructional practices (explicit instruction through video-modelling in combination with a guide; explicit instruction through videomodelling; guide) on socio-scientific content learning. The different instructional practices show how to reach an integrative solution regarding a socio-scientific controversy. 
2. To examine the relationship between the integration level of the argumentative syntheses produced by the students and their learning of socio-scientific content. Likewise, we aim to explore if the effect of instructional practices on learning of socio-scientific content is mediated by the learning of integration processes.

In keeping with these objectives, the initial hypotheses are as follows:

1. All participants will increase their scientific knowledge related to some socioscientific problems addressed during the intervention. However, students who receive both instructional aids (explicit instruction through video-modelling and guide) will get higher gains in terms of learning.

2. We expect a positive relation between the integration level of the argumentative syntheses and the learning of socio-scientific content achieved by the students. We also expect an indirect path whereby instructional practices affect students' outcomes on content learning by providing integration skills.

\section{Method}

\section{Participants}

Participants in this study included 216 students from eight complete third-grade classes (aged 14-15), attending three publicly funded secondary schools from Madrid, Spain. These three educational institutions were equivalent in terms of size and parents' socioeconomic backgrounds (medium-high). Classes were distributed between four intervention programs, which will be described later. The assignment of the classes to the four intervention programs was carried out taking into account the performance of the students in the subject Spanish language. Prior to implementation, we ensured that student assignment had resulted in intervention programs in which there was an equivalent ratio of students scoring high and low in this subject. We later verified through statistical analysis that the mean scores of the students in the different programs did not differ significantly regarding this variable $(F(3,183)=1.01 ; p=.39)$. Students and their legal guardians were asked to sign an informed consent document before participation in the study. The informed consent document was approved by an ethics committee and guaranteed the protection of the personal data, establishing the ethical principles and commitments that would guide participation.

Throughout the intervention, sample loss occurred. 65 students out of the total 216 who initially agreed to participate in the study, and whose parents had consented, did not attend all the intervention sessions or did not complete all the assessment tasks. These students were excluded from the analysis. Therefore, the final sample consisted of 151 participants (52\% were female and $48 \%$, male). None of these students had learning disabilities. 


\section{Instruments and material}

\section{Intervention programs}

We created four intervention programs, based on the combination of two instructional components-explicit instruction through video modelling (EI-component), and a guide (G-component). Participation in deliberative discussions about controversial socio-scientific topics was a common element in the four programs. The most complete program, DD $+\mathrm{G}+\mathrm{EI}$, included both elements and addressed the processes involved in reaching integrative solutions during deliberative discussions, with the additional support of the guide. The second program, DD +EI, included instruction about the integration processes through video modelling, but without the support of the guide. The third program, DD+G, involved the use of the guide, without any explicit instruction. Finally, in the fourth program, DD, students received neither explicit instruction nor the support of the guide. The intervention programs and their components are detailed in Table 1.

\section{Explicit Instruction (EI)}

The component of explicit instruction was adapted from Mateos et al. (2018). The objectives of this instruction were: (1) to teach students to achieve comprehensive solutions when opposing positions presented through several sources are discussed, and (2) to train students in writing integrative conclusions related to the controversies. The process of reaching an integrative solution during a deliberative discussion was illustrated as a seven-step procedure. The first step implied reading opposing texts about controversial issues. The second and the third steps showed how to identify arguments and counterarguments of each position. During the fourth step, students were taught to compare and to contrast both positions with the aim of reaching an integrative conclusion (fifth step). The sixth step focused on organising ideas to transfer them to the written text. Lastly, the seventh step required revising the written text. Although the steps were presented in a linear way for didactic reasons, the recursive nature of the process was explained to the students.

Instead of using a traditional method to provide explicit instruction to our participants, we employed the video modelling strategy. We recruited four volunteers who

Table 1 Components included in the intervention programs

\begin{tabular}{llll}
\hline & Components & & \\
\cline { 2 - 4 } & $\begin{array}{l}\text { Explicit instruction } \\
\text { with video modelling }\end{array}$ & Guide & $\begin{array}{l}\text { Participation in } \\
\text { deliberative discus- } \\
\text { sions }\end{array}$ \\
\hline DD+G+EI & $\mathrm{X}$ & $\mathrm{X}$ & $\mathrm{X}$ \\
$\mathrm{DD}+\mathrm{EI}$ & $\mathrm{X}$ & & $\mathrm{X}$ \\
$\mathrm{DD}+\mathrm{G}$ & & $\mathrm{X}$ & $\mathrm{X}$ \\
$\mathrm{DD}$ & & & $\mathrm{X}$ \\
\hline
\end{tabular}


were the same age as the study participants to simulate an expert discussion task. To guarantee a good performance, we provided them with a script in which four people discussed the advantages and disadvantages of alternative medicine. The discussion script reflected all the interactions corresponding to the seven stages of the explicit instructional process and their correct execution. The volunteers memorised the script and performed it while we videotaped them. We also asked volunteers to conduct two versions of the discussion; one version for the program in which the explicit instruction was combined with the guide $(D D+G+E I)$, and another version for the program in which the only assistance was the explicit instruction (DD $+\mathrm{EI})$. In the video recorded for $\mathrm{DD}+\mathrm{G}+\mathrm{EI}$ program, the volunteers held a discussion with the additional support of a guide that explained the stages comprised in the instructional process. Conversely, in the video recorded for the DD +EI program, the volunteers developed the same discussion but without any support tool. Both videos were later edited to facilitate the future modelling process with our students. We included titles for each of the steps, in order to focus the students' attention on the strategy being modelled in each phase.

\section{Guide (G)}

A guide adapted from previous studies (Mateos et al., 2018) was administered to $\mathrm{DD}+\mathrm{G}+\mathrm{EI}$ and $\mathrm{DD}+\mathrm{G}$ intervention programs. This guide included the following sections: a table with separate columns to fill in with the arguments from both positions, a text box with some strategies to establish relationships between positions, and a panel of questions to (1) guide the students in reaching an integrative conclusion after discussions (e.g., "Is there any way to reconcile the two positions?"), (2) write the integrative conclusion agreed by the group (e.g., "Is it better to start with the strongest argument or leave it to the end of the text?"), and (3) revise the final draft (e.g., "Has the conclusion of the group been expressed clearly in the text?").

\section{Argumentative exercises}

We elaborated a set of exercises similar to those employed in school to teach argumentation in a traditional way. These exercises consisted in answering several questions about two opinion articles, published in a national newspaper. Some examples of questions are: What is the topic of the articles? What audience are the texts aimed at? If you had to give them a title, what would it be? What are the characteristics of the vocabulary of the texts?

\section{Practice in small group discussions}

Within each class, students were organized in small groups composed by 4-5 students. The purpose of these activities was to read controversial socio-scientific texts, discuss them, reach integrative solutions considering both sides of the topic, and write down the conclusion elaborated by the group. Additionally, within each group, one member was designated as the leader. The teacher of each class, following some recommendations, conducted the assignment. Students designated as leaders had to 
be skilled in the following tasks: leading groups, managing time and actively participating in classroom dynamics. Leaders participated in a second round of discussion with the aim of reaching an even more integrative solution, based on the conclusions generated by their respective groups.

\section{Texts for the argumentative synthesis tasks and for discussion activities}

Four pairs of argumentative texts were elaborated. Two of them were administrated for the individual synthesis writing task at the beginning and at the end of the intervention. Texts were balanced at these two assessment moments. The other two pairs were employed for the discussion activities. Each pair of texts provided conflicting information about a controversial socio-scientific topic, representing a position in favour and another against the debate in question. Specifically, the topics were: risks and benefits of nuclear energy, risks and benefits of transgenic foods, risks and benefits of embryonic stem cell research and risks and benefits of plastic materials. Texts were equivalent in structure, length (between 700 and 780 words) number of arguments (6) and counterarguments (6).

\section{Learning content test}

A content test, intended to assess the learning about the scientific issues addressed in the texts, was designed. The test included the following two open-questions: what do you know about: (1) nuclear energy, (2) transgenic foods?

\section{Design and procedure}

We conducted a pre-post quasi-experimental study, randomized at classroom level. The independent variable was the "intervention program" with four levels $(\mathrm{DD}+\mathrm{G}+\mathrm{EI}$; DD + EI; DD + G; DD). The dependent variables were (1) the integration level of the syntheses, and (2) the learning of socio-scientific contents.

The study comprised a total of eight 50-min sessions, one per week over eight consecutive weeks and it was led by one of the researchers. Intervention was conducted as follows.

The first session was aimed at assessing students' prior knowledge about some of the socio-scientific topics that were to be addressed throughout the intervention. Students completed the learning content test for the first time.

In the second session, students from all programs were asked to elaborate an individual argumentative synthesis (prior individual synthesis). This prior synthesis was either about transgenic foods or nuclear energy since the texts were counterbalanced in pre-test and post-test. The instruction received by all the participants to write the initial synthesis was: You are going to read two texts about a highly debated topic in science (pros and cons of transgenic foods/nuclear energy). You should read the texts in the order in which they are presented. After that, you have to write an argumentative synthesis based on the texts you have read. Justify your conclusion with arguments, considering the information provided by both texts. You can read and 
consult the texts as many times as you need, underline, take notes and make drafts. After the synthesis was elaborated, students had to fill in the open-question of the learning content test related to the topic assigned.

In the third session, students from the different programs received specific instructions. In DD $+\mathrm{G}+\mathrm{EI}$ and $\mathrm{DD}+\mathrm{EI}$ programs, this session focused on developing explicit instructions through video modelling. The students of both programs watched the videos where the volunteers simulated an expert discussion about alternative medicine and reached an integrative solution. The video showed in the $\mathrm{DD}+\mathrm{G}+\mathrm{EI}$ program demonstrated how to hold a discussion with the support of a guide. By contrast, the students in the DD+EI program watched a video in which the volunteers developed a discussion without any external support. Both videos, which were approximately $15 \mathrm{~min}$ long, were explained by one of the researchers at the same time as they were being projected. The researcher paused the video after each stage of the explicit instruction procedure. At each pause, the researcher reflected with the students on what they had just seen, in order to promote the acquisition of the skills illustrated in the videos. In the $\mathrm{DD}+\mathrm{G}$ program, the instructions consisted in providing the students with the guide that they would use later during the discussions. During the 50-min session, the students were asked to read the guide carefully. To ensure that students were familiar with the tool, they were also asked to answer some reflective questions, e.g. "Have you ever used a tool like this? If yes, for what kind of tasks?" "Have you been surprised by any section in the guide? Why?", "Is the language in the guide clear enough?". The students in the DD program did not receive any instructions. They were asked to do the argumentation exercises described above. Despite the instructional differences, session 3 was the same length across all programs.

In the fourth session, discussion groups of 4-5 students were formed. Following the teacher's recommendations, one of the members of the group was designated as the leader. Both the student groups, as well as the designated leader of each group, were kept constant throughout all the discussion activities. The students received the following instructions to conduct the activity for session 4: The following task is a group activity, although you are going to start working individually. Each member has to read the pair of texts that you have been given. The texts address the pros and cons of using embryonic stem cells, which is a controversial topic nowadays. You must read the texts in the order in which they are presented. Later, you have to discuss the arguments of both texts with your group, in order to reach an integrative conclusion on the subject. To reach this conclusion it is necessary to assess the arguments stated by those who are in favour and those who are against, trying not to position yourselves on only one side of the problem. The conclusion has to refer to as many arguments from the texts as possible, and it must be written down. Within the group, there is a student who has been designated as the leader and whose name is on the sheet where you have to write the conclusion. This person has to ensure that the group completes the task in the 50-min session. Finally, keep in mind that, in the next session, we will conduct a new discussion in which only the leaders will participate. The leaders will have to communicate the conclusion reached in their groups before starting their discussion. It should be mentioned that, during the discussions, students from $\mathrm{DD}+\mathrm{G}+\mathrm{EI}$ and $\mathrm{DD}+\mathrm{G}$ programs worked with the support 
of the guide, although those of the $\mathrm{DD}+\mathrm{G}$ program did not receive instruction on how to use it.

Fifth session was dedicated to a "second round" of discussions, in which only the leaders participated. The rest of classmates acted as observers during the interactions. This new discussion was aimed at reaching an even more integrative solution, considering the conclusions elaborated by the groups in the previous session. The students received the following instructions to carry out the activity for session 5: As we anticipated in the previous session, today's activity consists in continuing the discussion on the subject matter of the texts that you have previously read. This second discussion aims to reach an even more complex conclusion about the controversy of the texts, if possible. The leaders of the groups will participate in this discussion, while the rest of the class will observe it without intervening. Each leader will first present the discussed conclusion that has been reached by their group. After that, the discussion will begin.

With the intention of keeping the attention of the rest of the students during the discussion developed by the leaders, they were given a sheet with the following question: Do you agree with the conclusion reached by the leaders? If you think there is a better solution to the problem, write it down and explain why.

Sessions 6 and 7 were analogous to sessions 4 and 5, respectively. Discussions were related to a new controversial socio-scientific topic (plastic materials), presented through pairs of argumentative texts as well.

Finally, in the eighth session, participants wrote another individual synthesis (final individual synthesis), and then, filled in the corresponding open-question from the learning content test. Students who worked with the texts about transgenic foods in the pre-test were assigned the topic of nuclear energy in the post-test (and vice versa). Table 2 presents a summary of the sessions.

\section{Coding system}

The quality of individual pre and post-test students' argumentative syntheses was evaluated based on the integration level. The assessment was conducted through a value scale, ranging from zero (minimum level of integration) to 10 (maximum level of integration). The scale (see Table 3) was adapted from previous studies (Mateos et al., 2018), and it was designed to rate the type and frequency of the argumentative strategies used by the students in their written texts (refutation strategies, weighing strategies or synthesising strategies).

The learning of socio-scientific contents was evaluated through the students' answers to the open-questions of the test. Students' responses were coded according to the number of units of information included. One point was assigned for each unit of information related to the topic. We considered a unit of information when it referred to the arguments and counterarguments of the sources, literally or paraphrasing them. For example, the student's answer transgenic foods need less water to grow up and they can contain more vitamins than regular foods was rated with two points since the student refers two units of information: (1) need less water to grow and (2) they can contain more vitamins. 


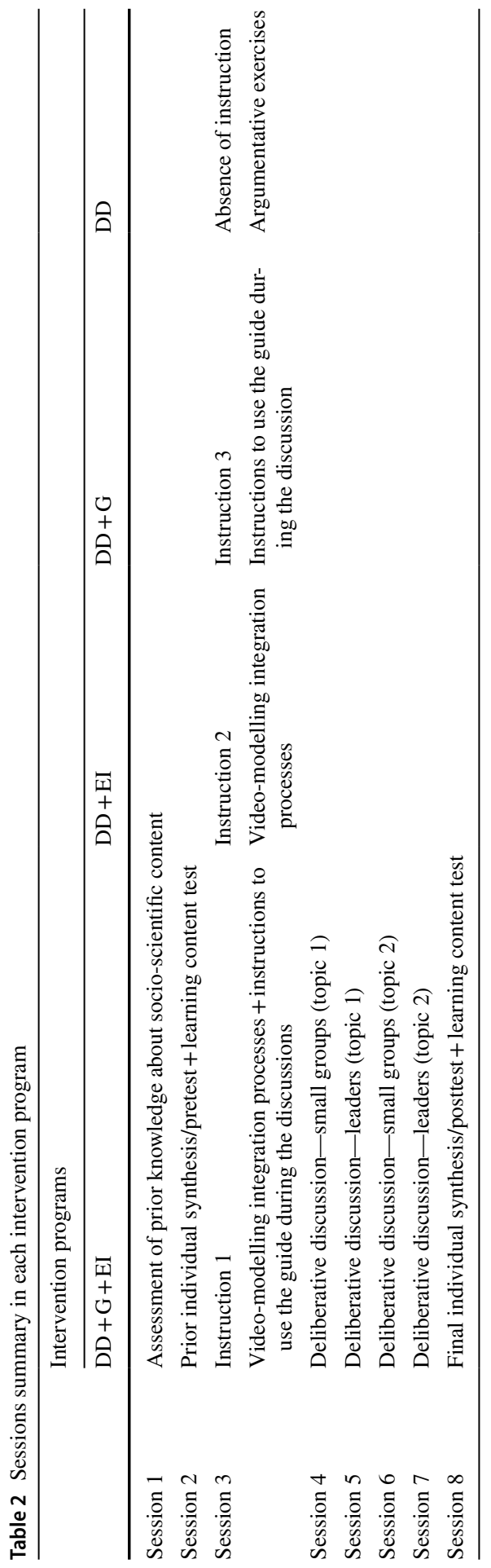




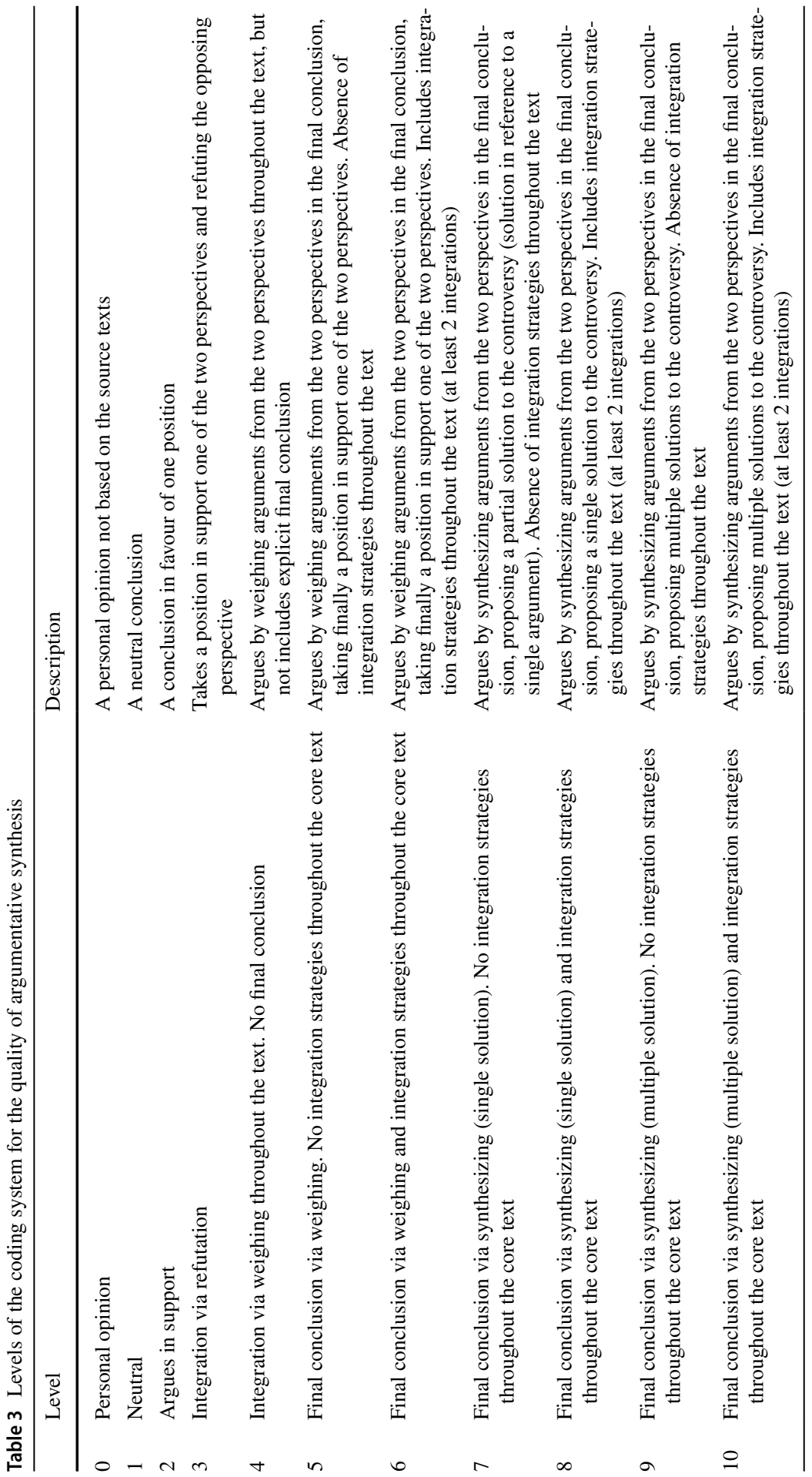


Two independent judges evaluated the integration level of the syntheses, codifying $30 \%$ of the 302 products elaborated by the participants before (prior syntheses) and after (final syntheses) the intervention programs. The two judges were part of the same research team, specialized in the field of argumentative synthesis writing. Therefore, both had extensive experience in evaluating the quality of this type of texts. The inter-judge agreement was calculated using the interclass correlation coefficient (ICC), based on absolute-agreement, 2-way mixed-effects model. An excellent degree of reliability was found for the integration variable. Same judges evaluated the learning of socio-scientific content, codifying $42 \%$ student's responses. An excellent degree of reliability was also reached for the content learning measures. Table 4 showed the mean intraclass correlation coefficients values found for the two dependent variables of the study. The cases in which there was no agreement were resolved by consensus; that is, both judges expressed the reasons why they had assigned their score, discussed the evidence on the presence of different argumentative strategies, and reached an agreement on the most appropriate score for the quality of the text. The remaining products (synthesis and the answers to the learning content test) were evaluated by one of researchers using the established criteria.

\section{Instructional fidelity}

To ensure the fidelity of the intervention's implementation, a script was prepared with the content to be covered in the instructional session of each intervention program. The same researcher author was in charge of implementing all the sessions in the four intervention programs. The researcher in charge made sure to follow the order and explanation for each component included in the script. Participants were not allowed to intervene during the instructional session to ensure that the information transmitted by the researcher was in accordance with the elaborated script.

\section{Results}

\section{Baseline comparisons}

\section{Prior knowledge about the socio-scientific topics}

Preliminary analyses were conducted to examine pre-intervention differences across prior knowledge on socio-scientific issues assessed. The $t$-test revealed statistically significant differences between the mean scores obtained in the initial evaluation

Table 4 Interclass correlation coefficient (ICC) measures

\begin{tabular}{llllll}
\hline Variable & \multirow{2}{*}{$\begin{array}{l}\text { ICC (95\% confi- } \\
\text { dence interval) }\end{array}$} & \multicolumn{4}{l}{ F test with true value 0} \\
\cline { 3 - 6 } & & Value & $d f 1$ & $d f 2$ & $p$ value \\
\hline Integration level & $.949(.92-.968)$ & 19.72 & 77 & 77 & $p<.001$ \\
Content learning & $.935(.856-.969)$ & 17.42 & 31 & 31 & $p<.001$ \\
\hline
\end{tabular}


question regarding transgenic foods and the question related to nuclear energy ( $t$ $(150)=11.7 ; p<.001)$. Before the intervention, the students had more knowledge about nuclear energy $(M=1.52 ; S D=1.39)$, than about transgenic foods $(M=.17$; $S D=.56)$.

We also examined the baseline differences between the intervention conditions in the prior knowledge about the socio-scientific issues. The analysis of variance did not reveal significant differences in the prior knowledge shown by the students of the different intervention programs, neither in relation to the topic of nuclear energy ( $F$ $(3,147)=.85, M S e=1.94, p=.47)$, nor in relation to the subject of transgenic foods $(F(3,147)=.82, M S e=.31, p=.49)$.

\section{Initial integration skills}

We conducted preliminary analysis to test the equivalence between the intervention groups, regarding the initial skills on argumentative synthesis writing; specifically, in relation to the ability to integrate arguments and counterarguments before the intervention. The analysis of variance did not show significant differences between the intervention conditions with respect to the integration level of the initial synthe$\operatorname{sis}(F(3,147)=2.09, M S e=6.77, p=.11)$.

\section{Preparing the data for content learning analysis}

Baseline comparisons revealed a lack of equivalence in the level of prior knowledge about the two socio-scientific topics (transgenic foods and nuclear energy). This imbalance led us to analyse the effect of the interventions on content learning for both topics separately. In order to conduct this analysis differentiated by topic, we had to take into account that socio-scientific texts were balanced at two assessment moments: students who worked with the texts about transgenic foods in the pre-test (session 2) dealt with the topic of nuclear energy in the post-test (session 8), and vice versa. Hence, we identified those participants who in the post-test filled in the test on transgenic foods or nuclear energy, and we compared their final scores with their initial scores in the same thematic questions assessed on prior knowledge test (session 1). Figure 1 shows a diagram of the procedure followed to analyse data related to content learning.

\section{Effects of the interventions on content learning about socio-scientific topics}

The results presented here refer to comparisons between the students' answer to prior knowledge test (session 1), and their answers to the final content test completed after the final argumentative synthesis (session 8).

To assess the intervention effects on the learning of the two specific socio-scientific contents, we conducted linear mixed models analyses. We started with a baseline model (M1) including random intercepts for students, to control for interindividual differences. In a second model (M2) we added the fixed effect of time-measurement occasions. Thirdly, we included the effect of the experimental 


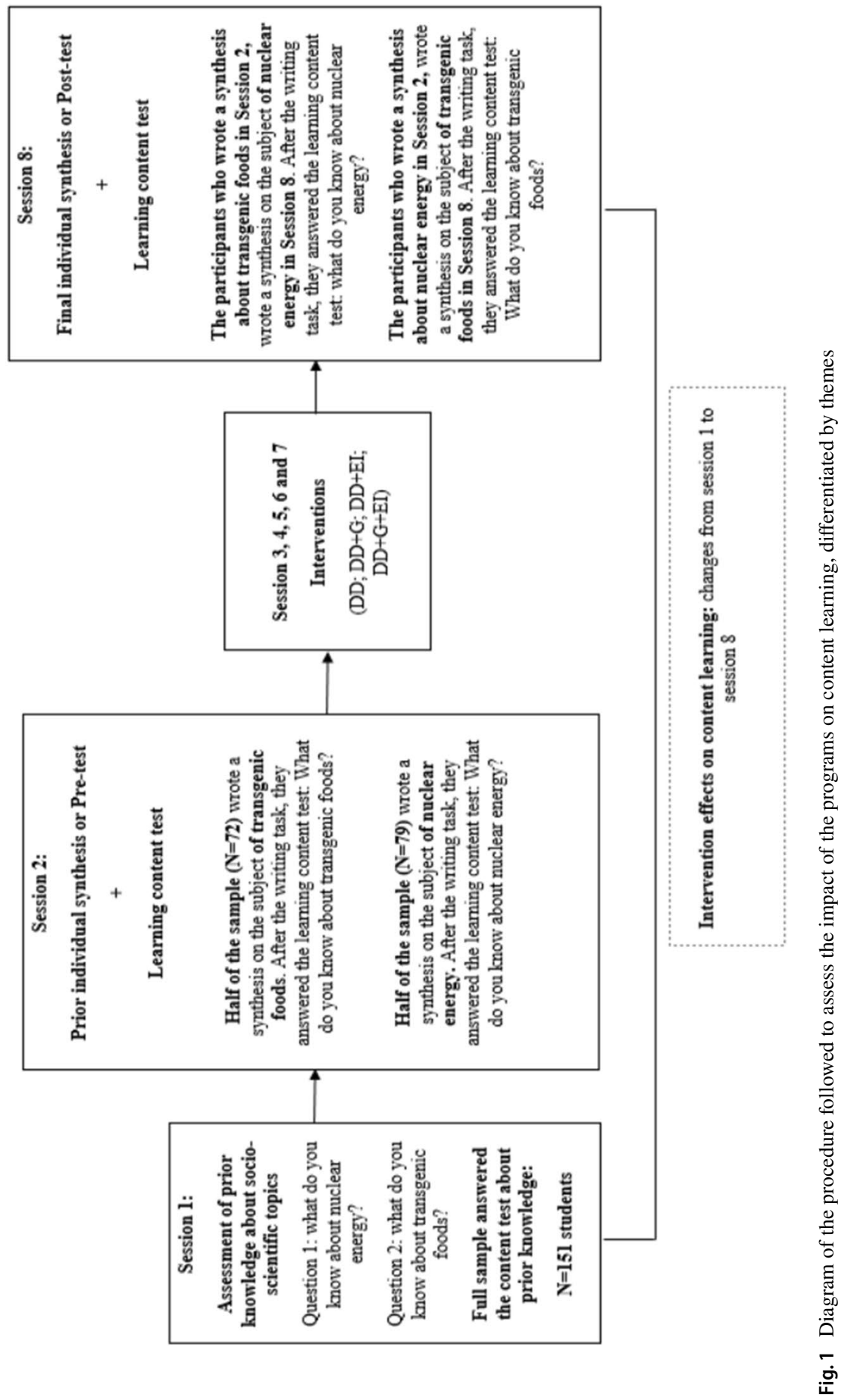


conditions (M3). Finally, we tested the interaction between the time and the experimental condition (M4). The outcome variable was the content learning i.e. the learning related to transgenic foods and the learning related to nuclear energy. The specified models were identical for both topics. The fit of the models and the significance of the parameters were evaluated taking into account the change in log-likelihood ratio.

Table 5 presents the fit of the models, as well as a comparison of the models, for the learning of both socio-scientific topics.

Based on the comparison of the four models for the learning related to transgenic foods we found that measurement occasion contributed significantly to the description of the data $\left(\chi^{2}(1)=162.611 ; p<.01\right)$. The knowledge about transgenic foods (assessed as the number of correct information units included in the student's answer) was greater on the post-test than on the prior content test. Neither the main effect of condition, nor the interaction between measurement occasion and condition reached significance.

Analogous results were obtained for the learning related to nuclear energy. From the comparison of the four models with respect to this socio-scientific topic we observed that measurement occasion contributed significantly to the description of the data $\left(\chi^{2}(1)=42.647 ; p<.01\right)$. The knowledge about nuclear energy was also greater on the post-test than on the prior content test. We did not find a main effect of condition and the interaction between the measurement occasion and the experimental condition was not significant either.

\section{Effects of the interventions on learning integration processes}

The results presented here refer only to comparisons between the pieces of writing that the students produced individually before (session 2) and after (session 8) the intervention.

Table 5 Fit of the models and comparisons for content learning

\begin{tabular}{|c|c|c|c|c|c|c|}
\hline & \multirow[t]{2}{*}{ Model } & \multirow[t]{2}{*}{$-2 \log l i k$} & \multicolumn{4}{|c|}{ Comparison of models } \\
\hline & & & Models & $\chi^{2}$ & $d f$ & $p$ \\
\hline \multicolumn{7}{|c|}{ Transgenic foods } \\
\hline Model 1 & & 698.314 & & & & \\
\hline Model 2 & $\mathrm{M} 1$ + time & 535.703 & 1 versus 2 & 162.611 & 1 & $<.01$ \\
\hline Model 3 & $\mathrm{M} 2+$ condition & 530.518 & 2 versus 3 & 5.185 & 3 & .16 \\
\hline Model 4 & $\mathrm{M} 3+$ time $*$ condition & 528.712 & 3 versus 4 & 1.806 & 3 & .61 \\
\hline \multicolumn{7}{|c|}{ Nuclear energy } \\
\hline Model 1 & & 550.88 & & & & \\
\hline Model 2 & M1 + time & 508.233 & 1 versus 2 & 42.647 & 1 & $<.01$ \\
\hline Model 3 & $\mathrm{M} 2+$ condition & 506.021 & 2 versus 3 & 2.212 & 3 & .53 \\
\hline Model 4 & M3 + time ${ }^{*}$ condition & 504.964 & 3 versus 4 & 1.057 & 3 & .79 \\
\hline
\end{tabular}


To contrast the effects of the four intervention programs on the integration learning we again conducted linear mixed models analyses. As we did to assess the effect of the programs on socio-scientific content learning, we started with a baseline model (M1) including random intercepts for students. In a second model (M2) we added the fixed effect of time-measurement occasions. Thirdly, we included the effect of the experimental conditions (M3). Finally, we tested the interaction between the time and the experimental condition (M4). In this occasion the outcome variable was the integration learning. The fit of the models and the significance of the parameters were evaluated taking into account the change in log-likelihood ratio.

Table 6 presents the fit of the models, as well as a comparison of the models, for the integration learning.

As shown Table 6, measurement occasion contributed significantly to the description of the data $\left(\chi^{2}(1)=81.057 ; p<.01\right)$. This result reveals that all students improved the level of integration of their syntheses. We also found a main effect of condition $\left(\chi^{2}(3)=18.056 ; p<.01\right)$. In this regard, the results of applying the Bonferroni post-hoc test showed that the level of integration of the final syntheses elaborated by students from DD+EI program was higher than that achieved by students in all the other conditions $(p<.01)$. Finally, the interaction between measurement occasion and condition did not reach significance i.e. students in the four experimental conditions improved the quality of their synthesis equally.

\section{Mediated effect of instructional practices on content learning about socio-scientific topics}

A mediation analysis was computed to examine the indirect effect of different instructional practices/intervention modality (predictor variable $[\mathrm{X}]$ ) on learning of socio-scientific content (criterion variable [Y]) through learning of integration argument-counterargument skills (proposed mediator $[\mathrm{M}]$ ). The indirect effect was tested using PROCESS (model 4), a conditional process modeling program that tests direct and indirect effects using an ordinary least squares-based (OLS) path analytical framework (Hayes, 2013; Preacher \& Hayes, 2004). Bias-corrected bootstrapping $(\mathrm{k}=5000)$ was used to generate a $95 \%$ confidence interval $(\mathrm{CI})$ to test the significance of the indirect effect (Preacher \& Hayes, 2004).

Table 6 Fit of the models and comparisons for integration learning

\begin{tabular}{|c|c|c|c|c|c|c|}
\hline & \multirow[t]{2}{*}{ Model } & \multirow[t]{2}{*}{$-2 \log l i k$} & \multicolumn{4}{|c|}{ Comparison of models } \\
\hline & & & Models & $\chi^{2}$ & $d f$ & $p$ \\
\hline \multicolumn{7}{|c|}{ Integration learning } \\
\hline Model 1 & & 1521.396 & & & & \\
\hline Model 2 & $\mathrm{M} 1+$ time & 1440.339 & 1 versus 2 & 81.057 & 1 & $<.01$ \\
\hline Model 3 & $\mathrm{M} 2+$ condition & 1422.283 & 2 versus 3 & 18.056 & 3 & $<.01$ \\
\hline Model 4 & $\mathrm{M} 3+$ time $*$ condition & 1418.597 & 3 versus 4 & 3.686 & 3 & .30 \\
\hline
\end{tabular}




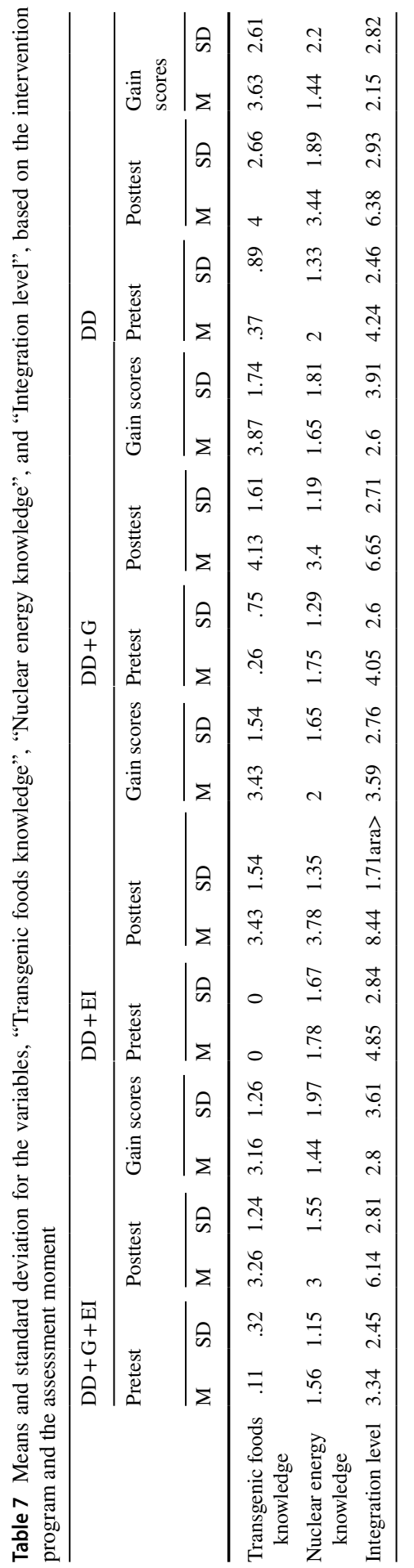


For the mediation analysis, both the criterion and the mediator variables were coded as learning gains (difference scores between post-test and pre-test for the integration level of the argumentative synthesis, and difference scores between posttest and pre-test for the knowledge about socio-scientific topics). See Table 7 for descriptive statistics related to criterion and mediator variables.

The predictor variable (Intervention modality) was a multicategorical variable. Given that we had four intervention groups (DD+G+EI: DD + EI; DD + G; DD), three dummy variables were created. We were interested in comparing the results of those students who received instructional aids against those who did not, so our

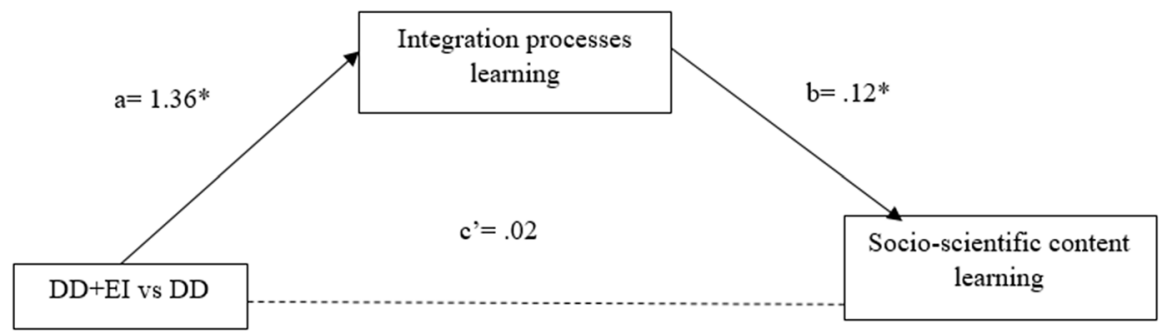

Fig. 2 Diagram of simple mediation analysis of instructional practice based on explicit instruction (vs. absence of instructional aids) on socio-scientific content learning through integration learning processes. Note: Dotted lines indicate non-significant relations. $* p<.05$

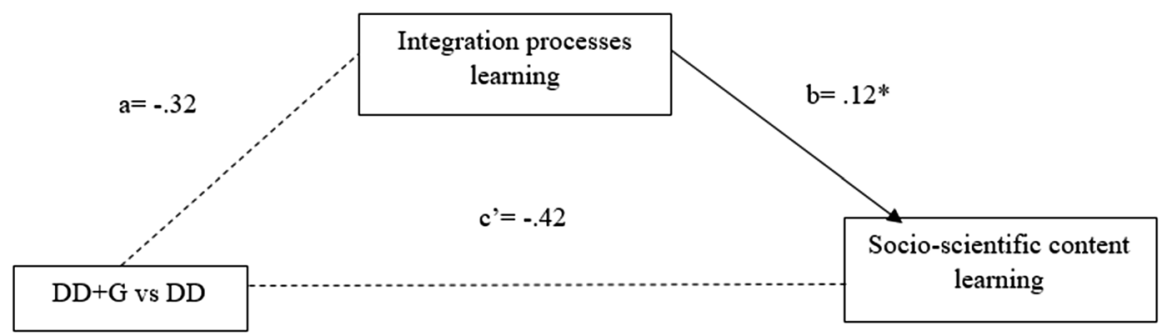

Fig. 3 Diagram of simple mediation analysis of instructional practice based on guide (vs. absence of instructional aids) on socio-scientific content learning through integration learning processes. Note: Dotted lines indicate non-significant relations. $* p<.05$

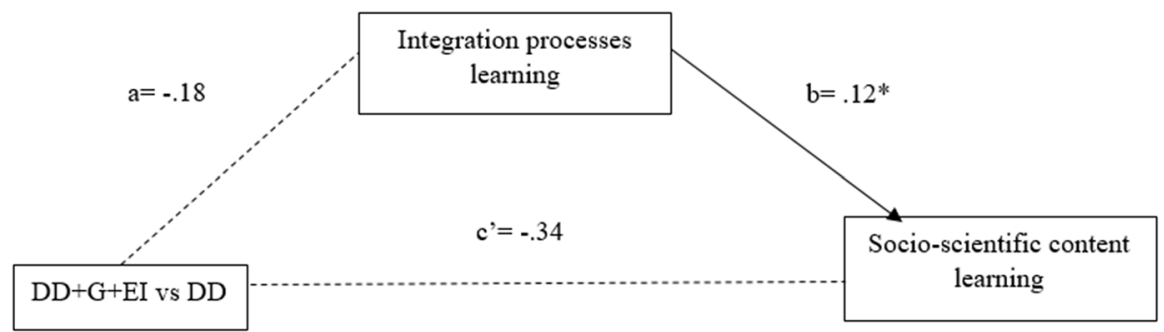

Fig. 4 Diagram of simple mediation analysis of instructional practice based on explicit instruction and guide (vs. absence of instructional aids) on socio-scientific content learning through integration learning processes. Note: Dotted lines indicate non-significant relations. $* p<.05$ 
baseline category was DD condition. See Figs. 2, 3, and 4 for a depiction of the mediation analysis, comparing each instructional practice (DD + G + EI; DD +EI; $\mathrm{DD}+\mathrm{G}$ ) with absence of instruction (DD condition).

Results indicated that receiving explicit instruction through video-modelling, versus the absence of instructional aids, significantly predicted learning gains in argument and counterarguments integration processes (path $\mathrm{a} ; t=2.25, p<.05$ ). In addition, greater levels of learning concerning the integration processes were significantly associated with greater socio-scientific knowledge showed by the students (path $\mathrm{b} ; t=2.33, p<.05$ ). However, a direct effect of explicit instruction on content learning about socio-scientific topics was not found (path $\mathrm{c}^{\prime} ; t=.06, p=.95$ ). In terms of the indirect effect, receiving explicit instruction were significantly predictive of greater socio-scientific content learning indirectly through greater integration processes learning (indirect effect $=.15 ; S E=.1 ; 95 \%$ CI [.006, .400].

On the other hand, the results show that receiving an instructional practice based on a guide, comparing with the absence of instruction, did not predict neither integration learning processes (path $\mathrm{a} ; t=-.52, p=.60$ ), nor learning of socio-scientific content (path c'; $t=1.14, p=.26$ ). On the contrary, a direct effect between argument and counterargument integration and socio-scientific knowledge acquisition was observed (path $\mathrm{b} ; t=2.44, p<.05$ ). Analogous results were found in the case of explicit instruction and guide combination, versus the absence of instructional practices (path a; $t=-.28, p=.78$; path c'; $t=-.87, p=.39$; path $\mathrm{b} ; t=2.37, p<.05$ ).

\section{Discussion}

The general objective of this study was to assess the effectiveness of four educational interventions, aimed at promoting learning of socio-scientific content in secondary school students. The intervention programs, which included deliberative dialogue activities, argumentative synthesis writing tasks and different instructional practices, lead to reach integrative solutions to controversial issues. Additionally, our goal was to explore the indirect effect of these different instructional practices on socio-scientific content learning, through the learning of argument and counterarguments integration processes. Argument and counterarguments integration processes were inferred through the quality of the argumentative syntheses elaborated by the students.

With respect to the first hypothesis, the results corroborate partially the assumptions presented. All participants from the study increased their scientific knowledge related to nuclear power and transgenic foods, which were socio-scientific topics about which they had little prior knowledge. These results are consistent with those obtained in previous empirical studies, in which the contribution of collaborative dialogue in learning scientific content has been revealed (Jiménez-Aleixandre, 2002; Larraín et al., 2019; von Aufschnaiter et al., 2008; Zohar \& Nemet, 2002). Even though deliberative dialogues were a constant element in the intervention programs and they were always reinforced with synthesis writing tasks, our results confirm that lessons based on dialogic activities provide students the opportunity to engage actively in science, enhancing their content understanding. Participating 
in argumentative oral activities promote the development of general and abstract knowledge structures or argument schemas, which constitute a type of knowledge that is transferable to other individual situations, allowing the student to solve complex issues (Larraín, 2017). Therefore, engagement in oral argumentation practice has allowed our students to accomplish knowledge goals even when pre-existing factual knowledge regarding the topic was minimal and superficial (Iordanou et al., 2019). Furthermore, our findings are aligned with those of Felton et al. (2009), showing that when individuals argue with a deliberative aim, seeking to reach a conclusion by contrasting the alternatives, they are capable of increasing their scientific knowledge. As mentioned above, our interventions combine deliberative dialogues with argumentative synthesis writing activities, which are writing tasks that stand out for their epistemic value. Argumentative synthesis writing from conflicting sources requires examining the relationship between arguments and counterarguments, in order to reconcile two perspectives about a controversy (Mateos et al., 2018). These integration processes promote constructive learning (Mateos et al., 2014; Nelson, 2008; Wiley et al., 2014) and they may have contributed to a better understanding of the sources which the learning questions were based on (Barzilai et al., 2018). Therefore, our findings show that interventions based on peergroup deliberative discussions about socio-scientific issues, in combination with argumentative synthesis writing from sources with conflicting information related to socio-scientific issues, contribute positively to the students' scientific literacy. These results are aligned with those of other research (Mason, 2001; Syh-Jong, 2007), in which it has been revealed the effectiveness of methodologies that integrate dialogic activities with writing tasks to facilitate scientific content learning. These interventions show that discussions are helpful to share, clarify, and distribute knowledge among peers, while analytical writing is an important tool for transforming rudimentary ideas into knowledge that is more coherent and structured. Discussion combined with writing lead science learning gains that could be maintained over time (Rivard \& Straw, 2000).

Contrary to prior expectations, we did not find an interaction effect between the instructional method and students' learning progress. Our hypothesis was that students who received instruction about how to reach an integrative solution regarding a socio-scientific controversy, through the combination of explicit instruction with video-modelling and guide, would have got higher gains in terms of learning. However, we did not observe a different progress depending on the instructional modality. This result differs from the findings of Zohar and Nemet (2002), whose study showed that integrating explicit teaching of argumentation into the lessons about human genetics through dilemmas enhances performance in biological knowledge. It should be noted that these authors do not only include in their study a session in which they teach the basic foundations of argumentation, but they also guide students on how to formulate arguments and rebuttals in the specific context of the dilemmas about genetics. That is, the dilemmas that presented the biological knowledge upon which the students were assessed included guide-questions on how to argue in relation to them. On the contrary, our instructional practices were based on socio-scientific content not assessed. The instructional practices of our study were focused on general strategies to reach integrative solutions to socio-scientific 
controversies. Both the explicit instruction through video modeling and the guide emphasized the processes of integration of arguments and counterarguments. We have taught domain-general strategies when the content learning test assessed individuals' knowledge about scientific concepts, instead of other processes related to scientific thinking as evidence evaluation skills (Zimmerman, 2000). This dissociation of our teaching process from the specific problems in which the students were evaluated may explain why we have not found a differential advance in those students who received instruction.

Furthermore, it is likely that deliberative interaction goals during the discussions, which are a common element in all the programs, have had a greater impact than the instructional practices themselves. This interpretation would be consistent with the results of Felton et al. (2009), who found that deliberative dialogues lead to science knowledge construction, without the need to complement them with explicit teaching processes on argumentative strategies. Another possible explanation is that instructional practices have influenced content learning through the improvement of argumentative synthesis writing, specifically through enhancing the integration level of the syntheses. This assumption could be tested through the mediation analysis linked to the second objective of the present study.

Given the lack of background, the second aim of this research was to explore the indirect effect of different instructional practices on socio-scientific content learning, through the learning of argument and counterarguments integration processes. We compared the results of those students who received instructional aids against those who did not, so our baseline category was DD condition. The mediation analysis showed a significant indirect effect of instruction on learning socio-scientific content through integration learning processes, but only in DD + EI condition. These findings reveal explicit instruction, through modelling and explanations of the processes involved in reaching integrative solutions to socio-scientific controversies, was the only instruction modality that had a direct effect on improving the quality of argumentative syntheses, considering their level of integration. And, in turn, it was through the improvement of synthesis writing that this instructional practice positively influenced content learning. It is worth mentioning that the participants from DD + EI program were exposed to a video in which several model students simulated an expert discussion to reach integrative solutions. The researcher also explained and made evident during the video the processes of selecting arguments from the sources, the process of comparing the arguments of one position and the other, the elaboration of an integrative conclusion, and the writing of an argumentative synthesis that contains this conclusion and its justification. It is likely that this explicit instruction, by explaining and making the processes underlying the task visible, promoted greater understanding and awareness of the task, greater self-regulation and, finally, better integration processes than in the rest of instructional conditions. In line with this result, several studies have demonstrated the essential role of explicit teaching to select arguments from sources and to integrate them using the strategies of weighing and synthesis (Casado-Ledesma et al., 2021; González-Lamas et al., 2016; Granado-Peinado et al., 2019; Mateos et al., 2018). Argumentative synthesis writing is a cognitive demanding task and the tendency to argue in favor of a single point of view-one-sided reasoning - is deeply rooted in the students. Instructional 
aids as guides or graphic tools do not seem enough to get students to write texts with a high level of integration (Ferretti \& Lewis, 2013). Although the guides may not be the most efficient aids to favor integration processes, an unexpected result of this study was not to find a direct effect of the instructional modality that combined explicit instruction with the guide, on the learning of integration processes. $\mathrm{DD}+\mathrm{G}+\mathrm{EI}$ was our most comprehensive instructional program and it was to be expected that it would have the greatest impact on learning integration processes and, therefore, indirectly, the one that most contributed to the learning of socio-scientific content. The results of the mediation analysis do not point in this direction and the reason may be the cognitive overload experienced by students in the most complex instructional condition. It is possible that the guide was a distracting element during discussions when students had previously received an explicit instruction session. Perhaps, the students from the $\mathrm{DD}+\mathrm{G}+$ EI program had difficulty handling several cognitively demanding tasks in a short session. During the deliberative discussions, students from this condition had to remember the video modelling of their prior instruction class and make strategic use of the guide and reach integrative solutions to the controversy in a 50-min session. Under these conditions, the combination of explicit instruction and the guide may not be the best teaching modality (Casado-Ledesma et al., 2021). In future research it will be necessary to address this limitation in order not to reduce the potential of the DD $+\mathrm{G}+$ EI condition.

On the other hand, we found an expected positive relation between argument and counterargument integration and socio-scientific knowledge in all the instruction conditions $(D D+G+E I ; D D+E I ; D D+G)$. Students who improved their argumentative synthesis writing, considering the integration level of the products, also achieved a significant progress in their socio-scientific knowledge. These results differ from those found by Larraín et al. (2018) in a similar study. They conducted an intervention with the goal of contrasting the role of individual argumentative skills in the effect of group argumentation on the learning of scientific content. Their findings were that pre- to post-gains in argumentation skills do not predict delayed learning gains. In their study, individual argumentation skills due to students' participation in group discussions did not account for content learning gains. However, it should be mentioned that these authors assessed individual writing skills through a test in which students formulated a point of view, justified it giving reasons and evaluated their own and others' arguments (Larraín et al., 2014). This writing task as a method of assessing skills differs considerably from that used in our study, which may explain the discrepancy in the findings. The difference in results is likely due to the epistemic potential of the individual writing activity considered in the research. Argumentative syntheses have been shown to be learning tasks that promote a deep understanding of the controversies presented through sources (Barzilai et al., 2018; Mateos et al., 2014, 2018; Nelson, 2008; Wiley et al., 2014). We have employed argumentative synthesis writing not only as a learning activity within the intervention, but also as a method of evaluating integration processes. Our results show the relationship between learning to write integrative syntheses and learning socio-scientific content. Therefore, we can conclude that exploring different perspectives with the goal of reaching conclusions that integrate aspect from both sides of an issue may activate knowledge 
building processes. The findings of our study, taken as a whole, support that argumentation learning and content learning are two inseparable processes when argumentative practices are developed around a specific domain of knowledge. Within this activity system (Engeström, 1987; Roth, 2004), in which discursive practice is combined with writing tasks, and in which oral and written argumentation is developed around a scientific content, the theoretical distinction between "learning to argue" and "arguing to learn" does not represent the comprehensive nature of the learning experience.

One of the limitations of the study is the brevity of the intervention. The fact that students have improved their socio-scientific knowledge only with eight program sessions illustrates the usefulness of deliberative dialogues and argumentative synthesis writing in teaching science, especially when the intervention includes explicit instruction processes. Nonetheless, it would be interesting to design a curricular intervention in order to implement this methodology in the teaching of various didactic units. This is the logic of the epiSTEMe ${ }^{\circledR}$ project (Howe et al., 2015), in which curriculum materials were developed to teach science and mathematics in secondary education through dialogic activities. Moreover, students were not assessed using delayed post-test measures, which does not allow us to affirm that the knowledge acquired is maintained after the intervention. Another relevant limitation is the type of assessment used to infer students' acquisition of knowledge. The content test designed evaluates concepts and declarative information on socio-scientific topics. In future research it would be necessary to measure higher-order skills related to scientific thinking as well as understanding of fundamental concepts. Students should be evaluated in the application of the principles of scientific inquiry to reasoning or problem solving situations (Zimmerman, 2000). Likewise, in future studies it would be interesting to evaluate the epistemic beliefs of the students, due to their role in learning the sciences (Nussbaum et al., 2008).

Despite the limitations, we believe that our findings provide interesting information for the educational community, since the interventions have been developed in a real scholar setting. Our study provides ecological empirical evidence about the benefits of learning environments based on deliberative dialogues and argumentative synthesis writing tasks to learn science. These activities themselves have great epistemic value, although when they also appear integrated in the same activity system, they lead to much more constructive learning processes promoting the acquisition of knowledge in a field as complex as science.

In summary, this research is particularly useful for innovating in science education. Science teachers, using this type of methodologies that combine the potential of dialogical activities and argumentative writing, supported by explicit instruction, will achieve an improvement in their students' learning outcomes.

Funding Open Access funding provided thanks to the CRUE-CSIC agreement with Springer Nature. The present study was supported by the Ministerio de Educación y Formación Profesional (Spain) under Grant for the Formación de Personal Investigador (FPU16/01454), and by the Ministerio de Ciencia e Innnovación State program oriented to the challenges of society (I+D+I) (PID2019-105250RB-I00). 


\section{Declarations}

Conflict of interest The authors declare that they have no conflict of interest.

Ethics approval All procedures performed in the study involving human participants were in accordance with the ethical standards of the institutional research committee of the Autónoma University of Madrid.

Consent to participate Informed consent was obtained from all individual participants included in the study.

Open Access This article is licensed under a Creative Commons Attribution 4.0 International License, which permits use, sharing, adaptation, distribution and reproduction in any medium or format, as long as you give appropriate credit to the original author(s) and the source, provide a link to the Creative Commons licence, and indicate if changes were made. The images or other third party material in this article are included in the article's Creative Commons licence, unless indicated otherwise in a credit line to the material. If material is not included in the article's Creative Commons licence and your intended use is not permitted by statutory regulation or exceeds the permitted use, you will need to obtain permission directly from the copyright holder. To view a copy of this licence, visit http://creativecommons.org/licen ses/by/4.0/.

\section{References}

Andriessen, J., \& Baker, M. (2014). Arguing to learn. In R. Sawyer (Ed.), The Cambridge handbook of the learning sciences (pp. 439-460). Cambridge University Press. https://doi.org/10.1017/cbo97 81139519526.027

Asterhan, C. S. C., \& Schwarz, B. B. (2007). The effects of monological and dialogical argumentation on concept learning in evolutionary theory. Journal of Educational Psychology, 99(3), 626-639. https://doi.org/10.1037/0022-0663.99.3.626

Asterhan, C. S. C., \& Schwarz, B. B. (2016). Argumentation for learning: Well-trodden paths and unexplored territories. Educational Psychologist, 51(2), 164-187. https://doi.org/10.1080/00461520. 2016.1155458

Barzilai, S., Zohar, A. R., \& Mor-Hagani, S. (2018). Promoting integration of multiple texts: A review of instructional approaches and practices. Educational Psychology Review, 30(3), 973-999. https://doi. org/10.1007/s 10648-018-9436-8

Bereiter, C., \& Scardamalia, M. (1987). The psychology of written composition. Lawrence Erlbaum Associates.

Casado-Ledesma, L., Cuevas, I., Van den Bergh, H., Rijlaarsdam, G., Mateos, M., Granado-Peinado, M., \& Martín, E. (2021). Teaching argumentative synthesis writing through deliberative dialogues: Instructional practices in secondary education. Instructional Science. https://doi.org/10.1007/ s11251-021-09548-3.

Cawthron, E. R., \& Rowell, J. A. (1978). Epistemology and science education. Studies in Science Education, 5(1), 31-59. https://doi.org/10.1080/03057267808559856

Dawson, V., \& Venville, G. J. (2009). High-school students' informal reasoning and argumentation about biotechnology: An indicator of scientific literacy? International Journal of Science Education, 31(11), 1421-1445. https://doi.org/10.1080/09500690801992870

Driver, R., Newton, P., \& Osborne, J. (2000). Establishing the norms of scientific argumentation in classrooms. Science Education, 84(3), 287-312. https://doi.org/10.1002/(SICI)1098-237X(200005)84: $3<287:$ :AID-SCE1>3.0.CO;2-A

Duschl, R. (2008). Science education in three-part harmony: Balancing conceptual, epistemic, and social learning goals. Review of Research in Education, 32(1), 268-291. https://doi.org/10.3102/00917 32x07309371

Duschl, R. A., \& Osborne, J. (2002). Supporting and promoting argumentation discourse in science education. Studies in Science Education, 38(1), 39-72. https://doi.org/10.1080/03057260208560187 
Engeström, Y. (1987). Learning by expanding: An activity-theoretical approach to developmental research. Orienta-Konsultit.

Erduran, S., Simon, S., \& Osborne, J. (2004). TAPping into argumentation: Developments in the application of Toulmin's argument pattern for studying science discourse. Science Education, 88, 915-933. https://doi.org/10.1002/sce.20012

Felton, M., Garcia-Mila, M., \& Gilabert, S. (2009). Deliberation versus dispute: The impact of argumentative discourse goals on learning and reasoning in the science classroom. Informal Logic, 29(4), 417-446. https://doi.org/10.22329/il.v29i4.2907

Ferretti, R. P., \& Lewis, W. E. (2013). Best practices in teaching argumentative writing. In S. Graham, C. A. MacArthur, \& Y. J. Fitzgerald (Eds.), Best practices in writing instruction (pp. 113-140). The Gilford Press.

Fulwiler, B. (2008). Writing in science: How to scaffold instruction to support learning. Heinemann.

Garcia-Mila, M., \& Andersen, C. (2007). Developmental change in notetaking during scientific inquiry. International Journal of Science Education, 29(8), 1035-1058. https://doi.org/10.1080/0950069060 0931103

Gayford, C. (2002). Controversial environmental issues: A case study for the professional development of science teachers. International Journal of Science Education, 24(11), 1191-1200. https://doi.org/10. 1080/09500690210134866

González-Lamas, J., Cuevas, I., \& Mateos, M. (2016). Arguing from sources: Design and evaluation of a programme to improve written argumentation and its impact according to students' writing beliefs. Infancia y Aprendizaje, 39(1), 49-83. https://doi.org/10.1080/02103702.2015.1111606

Granado-Peinado, M., Mateos, M., Martín, E., \& Cuevas, I. (2019). Teaching to write collaborative argumentative syntheses in higher education. Reading and Writing, 32(8), 2037-2058. https://doi.org/10. 1007/s11145-019-09939-6

Hayes, A. F. (2013). Introduction to mediation, moderation, and conditional process analysis: A regression-based approach. The Guilford Press. https://doi.org/10.1111/jedm.12050

Holbrook, J., \& Rannikmae, M. (2007). The nature of science education for enhancing scientific literacy. International Journal of Science Education, 29(11), 1347-1362. https://doi.org/10.1080/09500 690601007549

Howe, C., Ilie, S., Guardia, P., Hofmann, R., Mercer, N., \& Riga, F. (2015). Principled improvement in science: Forces and proportional relations in early secondary-school teaching. International Journal of Science Education, 37(1), 162-184. https://doi.org/10.1080/09500693.2014.975168

Iordanou, K., Kuhn, D., Matos, F., Shi, Y., \& Hemberger, L. (2019). Learning by arguing. Learning and Instruction, 63, 101-207. https://doi.org/10.1016/j.learninstruc.2019.05.004

Jiménez-Aleixandre, M. P. (2002). Knowledge producers or knowledge consumers? Argumentation and decision making about environmental management. International Journal of Science Education, 24(11), 1171-1190. https://doi.org/10.1080/09500690210134857

Kiuhara, S. A., Graham, S., \& Hawken, L. S. (2009). Teaching writing to high school students: A national survey. Journal of Educational Psychology, 101(1), 136-160. https://doi.org/10.1037/a0013097

Kuhn, D. (1991). The skills of argument. Cambridge University Press. https://doi.org/10.1017/cbo97 80511571350

Kuhn, D. (1993). Science as argument: Implications for teaching and learning scientific thinking. Science Education, 77(3), 319-337. https://doi.org/10.1002/sce.3730770306

Kuhn, D. (2005). Education for thinking. Harvard University Press.

Kuhn, D., Hemberger, L., \& Khait, V. (2015). Tracing the development of argumentive writing in a discourse-rich context. Written Communication, 33(1), 92-121. https://doi.org/10.1177/0741088315 617157

Larraín, A. (2017). Group-work discussions and content knowledge gains: Argumentative inner speech as the missing link? Learning, Culture and Social Interaction, 14, 67-78. https://doi.org/10.1016/j. lcsi.2017.04.002

Larraín, A., Freire, P., Grau, V., López, P., Salvat, I., Silva, M., \& Gastellu, V. (2018). The effect of peergroup argumentative dialogue on delayed gains in scientific content knowledge. New Directions for Child and Adolescent Development, 162, 67-87. https://doi.org/10.1002/cad.20263

Larraín, A., Freire, P., López, P., \& Grau, V. (2019). Counter-arguing during curriculum-supported peer interaction facilitates middle-school students' science content knowledge. Cognition and Instruction, 37(4), 453-482. https://doi.org/10.1080/07370008.2019.1627360 
Larraín, A., Freire, P., \& Olivos, T. (2014). Habilidades de argumentación escrita: Una propuesta de medición para estudiantes de quinto básico. Psicoperspectivas. Individuo y Sociedad, 13(1), 94-107. https://doi.org/10.5027/psicoperspectivas-vol13-issue1-fulltext-287

Lazarou, D., Erduran, S., \& Sutherland, R. (2017). Argumentation in science education as an evolving concept: Following the object of activity. Learning, Culture and Social Interaction, 14, 51-66. https://doi.org/10.1016/j.lcsi.2017.05.003

Leitão, S. (2000). The potential of argument in knowledge building. Human Development, 43(6), 332360. https://doi.org/10.1159/000022695

Mason, L. (2001). Introducing talk and writing for conceptual change: A classroom study. Learning and Instruction, 11(4-5), 305-329. https://doi.org/10.1016/s0959-4752(00)00035-9

Mateos, M., Martín, E., Cuevas, I., Villalón, R., Martínez, I., \& González-Lamas, J. (2018). Improving written argumentative synthesis by teaching the integration of conflicting information from multiple sources. Cognition and Instruction, 36(2), 119-138. https://doi.org/10.1080/07370008.2018.14253 00

Mateos, M., Solé, I., Martín, E., Cuevas, I., Miras, M., \& Castells, N. (2014). Writing a synthesis from multiple sources as a learning activity. In P. Klein, P. Boscolo, L. Kirkpatrick, \& C. Gelati (Eds.), Writing as a learning activity (pp. 168-190). Brill. https://doi.org/10.1163/9789004265011_009

Means, M. L., \& Voss, J. F. (1996). Who reasons well? Two studies of informal reasoning among children of different grade, ability, and knowledge levels. Cognition and Instruction, 14(2), 139-178. https://doi.org/10.1207/s1532690xci1402_1

Nelson, N. (2008). The reading-writing nexus in discourse research. In C. Bazerman (Ed.), Handbook of research on writing: History, society, school, individual, text (pp. 435-450). Lawrence Erlbaum.

Nickerson, R. S. (1998). Confirmation bias: A ubiquitous phenomenon in many guises. Review of General Psychology, 2(2), 175-220. https://doi.org/10.1037/1089-2680.2.2.175

Nussbaum, E. M. (2008a). Using argumentation vee diagrams (AVDs) for promoting argument-counterargument integration in reflective writing. Journal of Educational Psychology, 100(3), 549-565. https://doi.org/10.1037/0022-0663.100.3.549

Nussbaum, E. M. (2008b). Collaborative discourse, argumentation, and learning: Preface and literature review. Contemporary Educational Psychology, 33(3), 345-359. https://doi.org/10.1016/j.cedpsych. 2008.06.001

Nussbaum, E. M., \& Kardash, C. M. (2005). The effects of goal instructions and text on the generation of counterarguments during writing. Journal of Educational Psychology, 97(2), 157-169. https://doi. org/10.1037/0022-0663.97.2.157

Nussbaum, E. M., \& Schraw, G. (2007). Promoting argument-counterargument integration in students' writing. Journal of Experimental Education, 76, 59-92. https://doi.org/10.3200/jexe.76.1.59-92

Nussbaum, E. M., Sinatra, G. M., \& Poliquin, A. (2008). Role of epistemic beliefs and scientific argumentation in science learning. International Journal of Science Education, 30(15), 1977-1999. https://doi.org/10.1080/09500690701545919

OECD. (2018). The future of education and skills-Education 2030. OECD.

Patterson, E. W. (2001). Structuring the composition process in scientific writing. International Journal of Science Education, 23(1), 1-16. https://doi.org/10.1080/09500690117425

Preacher, K., \& Hayes, J. (2004). SPSS and SAS procedures for estimating indirect effects in simple mediation models. Behavior Research Methods, Instruments, \& Computers, 36, 717-731. https:// doi.org/10.3758/BF03206553

Rapanta, C., \& Christodoulou, A. (2019). Walton's types of argumentation dialogues as classroom discourse sequences. Learning, Culture and Social Interaction. https://doi.org/10.1016/j.1csi.2019. 100352

Rayner, G., \& Papakonstantinou, T. (2018). Interactions among students' prior learning, aspiration, confidence and university entrance score as determinants of academic success. Student Success, 9(2), 1-12. https://doi.org/10.5204/ssj.v9i2.438

Resnick, L. B., Asterhan, C. S. C., \& Clarke, S. N. (2015). Socializing intelligence through academic talk and dialogue. American Educational Research Association. https://doi.org/10.3102/ 978-0-935302-43-1

Rivard, L. P., \& Straw, S. B. (2000). The effect of talk and writing on learning science: An exploratory study. Science Education, 84(5), 566-593. https://doi.org/10.1002/1098-237X(200009)84:5<566:: AID-SCE2>3.0.CO;2-U

Roth, W. M. (2004). Activity theory and education: An introduction. Mind, Culture, and Activity, 11(1), 1-8. https://doi.org/10.1207/s15327884mca1101_1 
Sadler, T. D., Chambers, F. W., \& Zeidler, D. L. (2004). Student conceptualizations of the nature of science in response to a socioscientific issue. International Journal of Science Education, 26(4), 387409. https://doi.org/10.1080/0950069032000119456

Sadler, T. D., \& Zeidler, D. L. (2004a). Patterns of informal reasoning in the context of socioscientific decision making. Journal of Research in Science Teaching, 42(1), 112-138. https://doi.org/10.1002/tea.20042

Sadler, T. D., \& Zeidler, D. L. (2004b). The significance of content knowledge for informal reasoning regarding socioscientific issues: Applying genetics knowledge to genetic engineering issues. Science Education, 89(1), 71-93. https://doi.org/10.1002/sce.20023

Sampson, V., Enderle, P., Grooms, J., \& Witte, S. (2013). Writing to learn by learning to write during the school science laboratory: Helping middle and high school students develop argumentative writing skills as they learn core ideas. Science Education, 97(5), 643-670. https://doi.org/10.1002/sce.21069

Schwarz, B. B. (2009). Argumentation and learning. In N. Muller Mirza \& A. N. Perret-Clermont (Eds.), Argumentation and education: Theoretical foundations and practices (pp. 91-126). Springer. https://doi.org/10.1007/978-0-387-98125-3_4

Segev-Miller, R. (2007). Cognitive processes in discourse synthesis: The case of intertextual processing strategies. In G. Rijlaarsdam (Series Ed.), M. Torrance, L. van Waes, \& D. Galbraith (Vol. Eds.), Studies in writing: Volume 20-Writing and cognition: Research and applications. (pp. 231-250). Elsevier. https://doi.org/10.1108/s1572-6304(2007)0000020016

Spivey, N. N. (1997). Reading, writing and the making of meaning. Academic Press. https://doi.org/10. $2307 / 358470$

Syh-Jong, J. (2007). A study of students' construction of science knowledge: Talk and writing in a collaborative group. Educational Research, 49(1), 65-81. https://doi.org/10.1080/00131880701200781

Villarroel, C., Felton, M., \& Garcia-Mila, M. (2016). Arguing against confirmation bias: The effect of argumentative discourse goals on the use of disconfirming evidence in written argument. International Journal of Educational Research, 79, 167-179. https://doi.org/10.1016/j.ijer.2016.06.009

von Aufschnaiter, C., Erduran, S., Osborne, J., \& Simon, S. (2008). Arguing to learn and learning to argue: Case studies of how students' argumentation relates to their scientific knowledge. Journal of Research in Science Teaching, 45(1), 101-131. https://doi.org/10.1002/tea.20213

Walton, D. (2010). Types of dialogue and burdens of proof. In P. Baroni (Ed.), Computational models of argument (pp. 13-24). IOS Press.

Weinberger, A., \& Fischer, F. (2006). A framework to analyze argumentative knowledge construction in computer-supported collaborative learning. Computers \& Education, 46(1), 71-95. https://doi.org/ 10.1016/j.compedu.2005.04.003

Wiley, J., Steffens, B., Britt, M. A., \& Griffin, T. D. (2014). Writing to learn from multiple-source inquiry activities in history. In P. D. Klein, P. Boscolo, L. C. Kirpatrick, \& C. Gelati (Eds.), Studies in writing: Volume 28, writing as a learning activity (pp. 120-148). Brill. https://doi.org/10.1163/97890 04265011_007

Wolfe, C. R., Britt, M. A., \& Butler, J. A. (2009). Argumentation schema and the myside bias in written argumentation. Written Communication, 26(2), 183-209. https://doi.org/10.1177/0741088309 333019

Yore, L., Bisanz, G. L., \& Hand, B. M. (2003). Examining the literacy component of science literacy: 25 years of language arts and science research. International Journal of Science Education, 25(6), 689-725. https://doi.org/10.1080/09500690305018

Zeidler, D. L., Walker, K. A., Ackett, W. A., \& Simmons, M. L. (2002). Tangled up in views: Beliefs in the nature of science and responses to socioscientific dilemmas. Science Education, 86(3), 343-367. https://doi.org/10.1002/sce.10025

Zimmerman, C. (2000). The development of scientific reasoning skills. Developmental Review, 20(1), 99-149. https://doi.org/10.1006/drev.1999.0497

Zohar, A., \& Nemet, F. (2002). Fostering students' knowledge and argumentation skills through dilemmas in human genetics. Journal of Research in Science Teaching, 39, 35-62. https://doi.org/10. 1002/tea. 10008

Publisher's Note Springer Nature remains neutral with regard to jurisdictional claims in published maps and institutional affiliations. 


\section{Authors and Affiliations}

\section{Lidia Casado-Ledesma ${ }^{1}\left[\right.$ Isabel Cuevas ${ }^{1}\left(\mathbb{0} \cdot\right.$ Elena Martín $^{1}$}

Isabel Cuevas

isabel.cuevas@uam.es

Elena Martín

elena.martin@uam.es

1 Department of Developmental and Educational Psychology, Faculty of Psychology, Autónoma University of Madrid, C/Iván Pavlov, 6, Ciudad Universitaria de Cantoblanco, 28049 Madrid, Spain 